\title{
Outcome Transcatether Patent Ductus Arteriosus Closure in Children
}

\author{
Tri Rachmadijantoㅁ, Mahrus Abdur Rahman², I Ketut Alit Utamayasa², Taufiq Hidayat ${ }^{2}$ \\ ${ }^{1}$ Resident, ${ }^{2}$ Lecturer, Department of Child Health, Faculty of Medicine, Universitas Airlangga - Dr. Soetomo \\ General Academic Hospital, Surabaya, Indonesia
}

\begin{abstract}
Objective: To evaluated outcome transcatether PDA closure and differentiated LVEDD, EF pre and post transcatether PDA closure. Methods: Hospital registry was reviewed and data about patients characteristics, PDA size, device occluder and outcomes were retrieved. An descriptive analytic study with a retrospective design was conducted on all medical records of PDA pediatric patients who received definitive transcatheter PDA closure at IDIK and were treated at the Department of Child Health, Dr. Soetomo Hosptal from January 2017 until December 2019. The variables studied are: outcome transcatether PDA closure (complete closure, residual shunt, emboli device, obstruction pulmonaly artery, obstruction Aorta descendent, hemolysis, LVEDD and EF). Post catheterization included a follow up of immediately, 1 day, 1 month, 3 months, 6 months, and 12 months after catheterization. The data were processed and statistical comparative tests were carried out. Results: There were 101 subjects, of whom were 33 males, who underwent transcatether closure of PDA during study periode. The diameter PDA ranged from 1-7.5 mm, with median $3.4 \mathrm{~mm}$. Median age 4.3 years (4 months-18 years), median body weight was $15.4(5-45) \mathrm{kg}$. Device could be deployed in all patients, in which ADO I 65\%, ADO II 15\%, Nit Occlude 2\% and MFO 19\%. Immediately Complete closure was achieved in most patiens $(92,1 \%)$ and small residual shunt $(7,9 \%)$, no major complication during or after procedure. Most patient were discharged from hospital at 3 day after procedure. LVEDD and EF was decreased after intervention transcatether closure $(\mathrm{P}<0.05)$. There were no significant differences in LVEDD and EF transcatether based on closured method and sex. Conclusion: All patients showed complete closure during followed up. Transcatheter closure of PDA is safe and effective with shorter hospitalization and minimally complications.
\end{abstract}

Keywords : Transcatether closure, PDA, ADO I, ADO II, Nit-Occlude, MFO

\section{Introduction}

Patent Ductus Arteriosus (PDA) has been estimated to occur in 1 in 2500-5000 live births. As an isolated lesion, it represents $9-12 \%$ of all congenital heart

\section{Corresponding author :}

\section{Mahrus Abdur Rahman}

Department of Child Health, Faculty of Medicine, Universitas Airlangga - Dr. Soetomo General

Academic Hospital, Jl. Mayjend Prof Dr. Moestopo No. 6-8, Airlangga, Gubeng, Surabaya, East Java 60286, Indonesia, Mail: mahrus.a@fk.unair.ac.id diseases. PDA closure eliminates left to right shunt, volume overload of the left sided heart, the risk of pulmonary hypertension and the risk of infective endocarditis $^{(1)}$

The first transcatether to use a new method PDA closure successfully by combined artery and vein femoral approach. Many device occluder have been used extensively for transcatheter closure of PDA with variable degrees of success ${ }^{(2)}$. The use of the new Amplatzer Duct Occluder (ADO) in humans to close the PDA had been reported by the transcatheter approach ${ }^{(3)}$. This study to evaluate outcome PDA closure and analyze differentiated of LVEDD and Ejection Fraction pre and post transcatether PDA closure. 


\section{Subjects and Methods}

\section{Subjects}

A retrospective review was done for 109 procedures performed in 101 patients (33 males, 68 females) attempt to transcatether PDA closure during 3 years in Dr. Soetomo Hospital in Surabaya. Associated heart disorders were ventricular septal defect $(n=1)$, stenotic Aorta descedent (2), stenotic pulmonary valve (1), and Down syndrome (1). Transcatether PDA closure, we used a Nit-occlud device (PFM, Cologne, Germany), and an ADO I and ADO II device (AGA, MN, USA) and Konar-multifunctional occluder (Lifetech, Shenzhen, China).

\section{Methods}

This study is retrospective in children who underwent cardiac catetherization in attempt to close PDA by transcatether approach were evaluated. The procedure was performed by pediatric cardiologists and pediatricians at the Department of Child Health, Faculty of Medicine, Universitas Airlangga. We assessed PDA patients medical records from January 2017 to December 2019. All patients with isolated PDA and intervention with transcatheter PDA closure were included in this study. However, we excluded patients with incomplete medical records. No consent was required for this research. This study was approved by the Ethics Committee of Faculty of Medicine, Universitas Airlangga. We collected demographic data patients (age and sex), PDA size (categorized into large, moderate, and small), and outcomes PDA closure. The outcomes transcatether PDA closure were complete closure, incomplete closure/residual shunt, and emboli device, hemolysis, obstruction pulmonary artery, obstruction Aorta descendent, LVEDD and EF based on echocardiography.

\section{Statistical Analysis}

We analyzed the data with SPSS version 26.0. The categorical data were described by their absolute (n) and relative frequencies (\%). Meanwhile, the quantitative data were expressed as mean and standard deviation. We used Mann Whitney test and Anova to determine the differences LVEDD and EF pre and post transcatheter PDA closure. The difference is considered significant if the $p<0.05$

\section{Results}

We analyzed data from 101 patients who underwent transcatheter closure of PDA in our the study period. The mean of patients ages was $4.3( \pm 4.02)$ years old. The youngest was 2.5 months, and the oldest was 18 years old. Thirty-five $(34.7 \%)$ patients were male, and the remaining 66 patients $(65.3 \%)$ were female. We performed the closure using ADO I 65 (64.4\%) patients, ADO II 15 (14.9\%), Nit-Occlud 2 (2.0\%) and MFO in $19(18.8 \%)$ patients. We differentiated PDA closure method by transvenous 94 (93.1\%) and transarterial $7(6.9 \%)$. (Table 1$)$. The patients median weight was $15.47( \pm 9.95) \mathrm{kg}$, and the mean narrow size of the PDA was $3.4( \pm 1.67) \mathrm{mm}$. The most category of the PDA size is the moderate PDA $(1.5-3 \mathrm{~mm})$, which was found in 37 (36.6\%) patients (Table 1).

Outcomes of catheterization and intervention are described in Table 2. Sizes of ADO I ranged from 6 to $12 \mathrm{~mm}$, ADO II ranged from 4 to 6 , MFO ranged from 3 - 12. Most patients achieved immediately complete closure 93 (92.1\%) and eight who had minimally immediately residual shunt and achived complete closure after 1 month follow up. Emboli Device, obstruction Pulmonary artery and Aorta descendent, hemolysis post intervention were not found. The mean LVEDD and EF decreased from $35.62 \mathrm{~mm}$ and $71.03 \%$ before pre intervention and $31.02 \mathrm{~mm}$ and $68.88 \%$ one day post intervention. 
Table 1. Participant characteristics

\begin{tabular}{|c|c|}
\hline Variable & value \\
\hline $\begin{array}{l}\text { Gender } \\
\text { Male } \\
\text { Female }\end{array}$ & $\begin{array}{l}35(34.7 \%) \\
66(34.3 \%)\end{array}$ \\
\hline $\begin{array}{l}\text { Age } \\
<1 \text { years old } \\
<5 \text { years old } \\
>5 \text { years old }\end{array}$ & $\begin{array}{l}52.4 \pm 50.7 \\
21(20.8 \%) \\
41(40.6 \%) \\
39(38.6 \%)\end{array}$ \\
\hline Body weight & $15.5 \pm 9.9$ \\
\hline Body height & $94.3 \pm 27.7$ \\
\hline $\begin{array}{l}\text { Length of hospitalization } \\
\qquad \begin{array}{l}3 \text { days } \\
4 \text { days } \\
5 \text { days } \\
6 \text { days }\end{array}\end{array}$ & $\begin{array}{c}3.6 \pm 0.8 \\
56(55.4 \%) \\
28(27.7 \%) \\
15(14.9 \%) \\
2(2.0 \%)\end{array}$ \\
\hline $\begin{array}{l}\text { Type PDA } \\
\text { Type A } \\
\text { Type B } \\
\text { Type C } \\
\text { Type D } \\
\text { Type E }\end{array}$ & $\begin{array}{c}101 \\
0 \\
0 \\
0 \\
0\end{array}$ \\
\hline $\begin{array}{l}\text { Size PDA } \\
<1.5 \mathrm{~mm} \\
1.5-3 \mathrm{~mm} \\
3-5 \mathrm{~mm} \\
>5 \mathrm{~mm}\end{array}$ & $\begin{array}{c}6(5.9 \%) \\
37(36.6 \%) \\
35(34.6 \%) \\
23(22.7 \%)\end{array}$ \\
\hline $\begin{array}{c}\text { Transcatheter PDA closure method } \\
\text { Transvenous } \\
\text { Transarterial }\end{array}$ & $\begin{array}{c}94(93.1 \%) \\
7(6.9 \%)\end{array}$ \\
\hline $\begin{array}{c}\text { Device Occluder } \\
\text { ADO I } \\
\text { ADO II } \\
\text { Nit-occlude } \\
\text { MFO }\end{array}$ & $\begin{array}{c}65(64.4 \%) \\
15(14.9 \%) \\
2(2.0 \%) \\
19(18.8 \%)\end{array}$ \\
\hline Pulmonary artery pressure & $25.1 \pm 9.9$ \\
\hline $\begin{array}{c}\text { Patient history } \\
\text { Down syndrome } \\
\text { PDA in family history } \\
\text { Ventricular septal defect } \\
\text { Stenotic Aorta } \\
\text { Stenotic Pulmonal }\end{array}$ & $\begin{array}{l}1 \\
1 \\
3 \\
2 \\
1\end{array}$ \\
\hline
\end{tabular}


Table 2. Outcome transcatether PDA closure

\begin{tabular}{|c|c|c|c|c|c|c|}
\hline Outcome & Immediately & $\mathbf{1}$ day & $\mathbf{1}$ month & $\mathbf{3}$ month & $\mathbf{6}$ month & $\mathbf{1 2}$ month \\
\hline Complete closure & 93 & 93 & 101 & 101 & 101 & 101 \\
Residual shunt & 8 & 8 & 0 & 0 & 0 & 0 \\
Emboli device & 0 & 0 & 0 & 0 & 0 & 0 \\
Obstruction Pulmonary artery & 0 & 0 & 0 & 0 & 0 & 0 \\
Obstruction Aortic descendent & 0 & 0 & 0 & 0 & 0 & 0 \\
Hemolysis & 0 & 0 & 0 & 0 & 0 & 0 \\
\hline
\end{tabular}

\section{Discussion}

In this study, minimally residual shunts were found in the MFO occluders (2), ADO I (4), Nit-O (1), ADO II (1). On evaluation 1 month after the procedure, no residual shunt was found. The meta-analysis of transcatheter PDA closure showed a success rate of $92.2 \%{ }^{(4)}$. In the study of the outcome of PDA closure with Nit-Occlud and ADO I, small residual shunt results were obtained in Nit-Occlud (70\%) and ADO I (59\%). The residual shunt on Nit-Occlude was not seen after 4 hours of evaluation (90\%) and complete closure occurred after 2 months and 6 months of evaluation ${ }^{(5)}$. Immediately residual shunts are seen more frequently in nit-occlud compared to ADO I ${ }^{(6)}$. The residual shunt mechanism on the nit-occud is seen from the middle of the device which is different from the residual shunt seen in ADO I such as the formation of smoky (foaming) ${ }^{(3)}$. The mechanism of thrombus formation is assisted by the material contained in the occluder device on the MFO with a polytetrafluoroethylene (PTFE) membrane, on Nit-O assisted by a Nitinol layer, on ADO I and da ADO II with Polyester fabric ${ }^{(7)}$.

The results of this study are in accordance with those obtained by other researchers ${ }^{(8)}$. LVEDD decreased significantly after PDA closure with $p$ value $<$ $0.001^{(9)}$. In the evaluation of left ventricular dysfunction after transcater PDA closure, a significant decrease in LVEDD was found (Kim, 2008). The study of immediate and short-term changes in left ventricular diastolic and systolic function after transcatheter PDA closure showed a significantly decreased LVEDD value with $\mathrm{p}<0.001^{(10)}$. Closure of PDA can cause decreased of shunt flow from the ductus arteriousus to the pulmonary artery which results in the volume and size of the left heart being reduced compared to before PDA closure ${ }^{(11)}$.

The study of immediate and short-term changes in left ventricular diastolic and systolic function after transcatheter PDA closure showed a significantly decreased LVEF value with $\mathrm{p}<0.001^{(10)}$. Research on changes in left ventricular systolic function after transcatether PDA closure showed a decrease in $\mathrm{EF}^{(12)}$. A study on the comparison of outcomes for transcatether PDA closure in children and adults showed a decrease in EF values in both ${ }^{(13)}$.

Left ventricular volume overload is often seen in PDA and appears to be necessary to increase cardiac output by responding to the Frank Starling mechanism through stretching of the left ventricular muscle fibers, resulting in increased contractility and increased systolic function to overcome left to right shunts and maintain systemic circulation. According to the study, reported that relatively large PDA closure results in a sudden decrease in excessive left ventricular volume, thereby reducing muscle fiber stretch and decreasing systolic function. Changes after loading may be another contributing factor that affects the decreased left ventricular systolic function. Before closing, the left ventricle ejects blood both into the high resistance systemic circulation and through the PDA into the low resistance pulmonary circulation, after the PDA closure the left ventricle ejects blood only into the high resistance systemic circulation $^{(14)}$. Closure of the PDA will result in loss 
of the aortic to pulmonary shunt resulting in a decrease in left ventricular preload. However, closure of PDA results in an increase in left ventricular afterload due to loss of circulation to the lungs. There is a phenomenon of "afterload mismatch" where a simultaneous decrease in LV preload and an increase in left ventricular afterload results in LV systolic dysfunction ${ }^{(15)}$. In a study on the effect of PDA closure on left ventricular volume and function, there was a recovery of left ventricular function after a 6-month observation period ${ }^{(16)}$. Study to evaluated large PDA closure with transcatheter and surgery have shown recovery of left ventricular function after 6 months ${ }^{(11)}$. Research on changes in left ventricular function and remodeling after PDA closure in adolescents showed that $11 \%$ of patients had persistent decrease in left ventricular function ${ }^{(12)}$.

\section{Conclusion}

There was $92.1 \%$ complete closure immediately after closure of the PDA transcatheter. There was residual shunt after closure $7.92 \%$ immediately after closure of the PDA transcatheter. There were no ADO device embolism, hemolysis, pulmonary artery obstruction, descending aortic obstruction after transcatheter PDA closure. There were differences in LVEDD and ejection fraction before and after transcatheter of the PDA closure

\section{Funding: None.}

Conflict of Interest: The authors declare that they have no conflict of interest.

Ethical Approval: We have conducted an ethical approval base on Declaration of Helsinki at Ethical Committee in Dr. Soetomo General Academic Hospital, Surabaya, Indonesia.

\section{References}

1. Schneider DJ. The patent ductus arteriosus in term infants, children, and adults. Seminars in perinatology. 2012;36(2):146-53.

2. Baruteau AE, Hascoët S, Baruteau J, Boudjemline Y, Lambert V, Angel CY, et al. Transcatheter closure of patent ductus arteriosus: past, present and future. Archives of cardiovascular diseases.
2014;107(2):122-32.

3. Masura J, Gavora P, Podnar T. Transcatheter occlusion of patent ductus arteriosus using a new angled Amplatzer duct occluder: initial clinical experience. Catheterization and cardiovascular interventions : official journal of the Society for Cardiac Angiography \& Interventions. 2003;58(2):261-7.

4. Backes $\mathrm{CH}$, Rivera BK, Bridge JA, Armstrong AK, Boe BA, Berman DP, et al. Percutaneous Patent Ductus Arteriosus (PDA) Closure During Infancy: A Meta-analysis. Pediatrics. 2017;139(2).

5. Hiremath G, Aggarwal V, Soule K, Bass JL. Immediate angiographic residual shunt using the Nit-Occlud device for patent ductus arteriosus closure. Postepy w kardiologii interwencyjnej $=$ Advances in interventional cardiology. 2020;16(4):460-5.

6. Ghasemi A, Pandya S, Reddy SV, Turner DR, Du W, Navabi MA, et al. Trans-catheter closure of patent ductus arteriosus-What is the best device? Catheterization and cardiovascular interventions : official journal of the Society for Cardiac Angiography \& Interventions. 2010;76(5):687-95.

7. Vijayalakshmi IB, Chitra N, Rajasri R, Vasudevan $\mathrm{K}$. Initial clinical experience in transcatheter closure of large patent arterial ducts in infants using the modified and angled Amplatzler duct occluder. Cardiology in the young. 2006;16(4):378-84.

8. Zhang CJ, Huang YG, Huang XS, Huang T, Huang WH, Xia CL, et al. Transcatheter closure of large patent ductus arteriosus with severe pulmonary arterial hypertension in adults: immediate and twoyear follow-up results. Chinese medical journal. 2012;125(21):3844-50.

9. Agha HM, Hamza HS, Kotby A, Ganzoury MEL, Soliman N. Predictors of transient left ventricular dysfunction following transcatheter patent ductus arteriosus closure in pediatric age. Journal of the Saudi Heart Association. 2017;29(4):244-51.

10. Gupta SK, Krishnamoorthy K, Tharakan JA, Sivasankaran S, Sanjay G, Bijulal S, et al. Percutaneous closure of patent ductus arteriosus in children: Immediate and short-term changes in left ventricular systolic and diastolic function. Annals of pediatric cardiology. 2011;4(2):139-44.

11. Galal MO, Amin M, Hussein A, Kouatli A, Al-Ata J, Jamjoom A. Left ventricular dysfunction after 
374 Medico-legal Update, October-December 2021, Vol.21, No. 4 closure of large patent ductus arteriosus. Asian cardiovascular \& thoracic annals. 2005;13(1):24-9.

12. Jeong YH, Yun TJ, Song JM, Park JJ, Seo DM, Koh $\mathrm{JK}$, et al. Left ventricular remodeling and change of systolic function after closure of patent ductus arteriosus in adults: device and surgical closure. American heart journal. 2007;154(3):436-40.

13. Kanabar K, Bootla D, Kaur N, Pruthvi CR, Krishnappa D, Santosh K, et al. Outcomes of transcatheter closure of patent ductus arteriosus with the off-label use of large occluders ( $\geq 16 \mathrm{~mm})$. Indian heart journal. 2020;72(2):107-12.
14. Coceani F. Therapeutic manipulation of the ductus arteriosus: current options and future prospects. Polskie Archiwum Medycyny Wewnetrznej. 2014;124(1-2):58-64.

15. Ross J, Jr. Afterload mismatch and preload reserve: a conceptual framework for the analysis of ventricular function. Progress in cardiovascular diseases. 1976;18(4):255-64.

16. Elsaughier SM, Ghaleb R, Mansour H. Effect of time delay of PDA closure on the aortic stiffness index and its relationship with cardiac function. Cardiovascular journal of Africa. 2019;30(3):1516. 